Obesity (Silver Spring). 2013 March ; 21(3): 621-628. doi:10.1038/oby.2012.91.

\title{
Neighborhood health-promoting resources and obesity risk (the Multi-Ethnic Study of Atherosclerosis)
}

\author{
Amy H. Auchincloss, PhD, MPH, \\ Department of Epidemiology and Biostatistics, Drexel University School of Public Health. 1505 \\ Race Street, 6th Floor (Mail Stop 1033). Philadelphia, PA 19102, Telephone: (215)762-2056 \\ FAX: (215)762-1174 \\ Mahasin S. Mujahid, \\ Department of Epidemiology, University of California Berkeley, School of Public Health Berkeley, \\ $\mathrm{CA}$ \\ Mingwu Shen, MS, \\ University of Michigan School of Public Health, Department of Epidemiology, Ann Arbor, MI \\ Erin D. Michos, MD, MHS, \\ Assistant Professor of Medicine, Division of Cardiology, Johns Hopkins School of Medicine \\ Baltimore, MD \\ Melicia C. Whitt-Glover, Ph.D., FACSM, and \\ President \& CEO, Gramercy Research Group (Winston-Salem, NC) \\ Ana V. Diez Roux, MD, PhD, MPH \\ University of Michigan School of Public Health, Department of Epidemiology Ann Arbor, MI \\ Amy H. Auchincloss: aha27@drexel.edu
}

\section{Abstract}

While behavioral change is necessary to reverse the obesity epidemic, it can be difficult to achieve and sustain in unsupportive residential environments. This study hypothesized that environmental resources supporting walking and a healthy diet are associated with reduced obesity incidence. Data came from 4008 adults aged 45-84 at baseline who participated in a neighborhood ancillary study of the Multi-Ethnic Study of Atherosclerosis. Participants were enrolled at 6 study sites at baseline (2000-2002) and neighborhood scales were derived from a supplementary survey that asked community residents to rate availability of healthy foods and walking environments for a one-mile buffer area. Obesity was defined as body mass index (BMI) $>=30 \mathrm{~kg} / \mathrm{m}^{2}$. Associations between incident obesity and neighborhood exposure were examined using proportional hazards and generalized linear regression. Among 4008 non-obese participants, 406 new obesity cases occurred during 5 years of follow-up. Neighborhood healthy food environment was associated

Users may view, print, copy, and download text and data-mine the content in such documents, for the purposes of academic research, subject always to the full Conditions of use:http://www.nature.com/authors/editorial_policies/license.html\#terms

Correspondence to: Amy H. Auchincloss, aha27@drexel . edu.

DISCLOSURE STATEMENT

The authors have no conflict of interest to disclose. 
with $10 \%$ lower obesity incidence per standard deviation increase neighborhood score. The association persisted after adjustment for baseline BMI and individual level covariates (HR 0.88, 95\% CI: $0.79,0.97$ ), and for correlated features of the walking environment but confidence intervals widened to include the null (HR 0.89, 95\% CI: 0.77, 1.03). Associations between neighborhood walking environment and lower obesity were weaker and did not persist after adjustment for correlated neighborhood healthy eating amenities (HR 0.98, 95\% CI 0.84, 1.15). Altering the residential environment so that healthier behaviors and lifestyles can be easily chosen may be a pre-condition for sustaining existing healthy behaviors and for adopting new healthy behaviors.

\section{Keywords}

Adult; Health Behavior; Obesity/*epidemiology; Residence Characteristics; Longitudinal Studies; Geographic Information Systems; Environment Design; Public Health; Risk Factors

\section{INTRODUCTION}

Adult obesity is associated with numerous morbidities including higher risk of type 2 diabetes, hypertension, and heart disease.[1, 2] In the US, unhealthy weight gain is common among all ages, including older adults who are past mid-life [3]. To decrease the prevalence of obesity, a multilevel, multifaceted public health approach is needed that includes altering external stimuli that encourage normative behaviors of unhealthy eating and physical inactivity.[4]

Recent interest in the effects of the built-environment on health behaviors and health outcomes is motivated by potential population health impacts from interventions or policies that affect the built environment. Cross-sectional studies have investigated associations of the local food and physical activity environments with body mass index (BMI). The presence of supermarkets near one's residence has generally been found to be associated with lower prevalence of BMI or obesity.[5-7] Cross-sectional time series has also found associations between increases in neighborhood food stores offering predominantly unhealthy foods and increases in obesity.[8] To date, evidence of cross-sectional associations between residential neighborhood "walkability" -- neighborhoods thought to be highly walkable -- with adult physical activity (PA) and obesity is mixed,[9] but has generally pointed toward an association between low walkability and overweight/obesity. [10] This is likely due at least in part to associations between walkable neighborhoods and energy expenditure via transportation-related PA and overall adult PA.[11, 12] A recent cross-sectional analysis by Mujahid et al.[13] using data from the Multi-Ethnic Study of Atherosclerosis (MESA) linked to a community survey that rated environments on the suitability for walkability and availability of healthy foods found a negative relationship with adult BMI independent of age, race/ethnicity, education, and income. A number of other studies have examined the potential contribution of neighborhood environment to adult obesity. However, causal inference from all of the aforementioned cross-sectional analyses is limited because of the inability to determine whether weight gain preceded the neighborhood exposure. 
Expert reviews have called for longitudinal studies examining neighborhood characteristics and incident obesity because they would strengthen inferences regarding causal effects of these environments.[14] To date, longitudinal studies have primarily examined associations between neighborhood socio-economic status (SES) and weight gain or incident obesity and generally found neighborhood deprivation associated with obesity.[15-17] One study went beyond neighborhood SES to examine whether specific features of neighborhoods relate to BMI change. Berry et al (2010) [18] examined whether walkability (using a GIS-derived walkability index plus a self-perceived built environment index derived from a 10-item questionnaire that included road traffic) and neighborhood socio-economic status were associated with BMI change after six years; only neighborhood socio-economic status and participant-reported road traffic showed the expected association. Generalizability is a limitation of the longitudinal studies to date since these studies were conducted only among subgroups and in some cases used self-report weight (Black women [16, 17]) and/or were conducted outside the US $[15,18]$ where neighborhood environments are likely quite different.

To date, no study has examined associations between specific neighborhood features, namely walkability and healthy food resources, and incident obesity. We used longitudinal data from a large multiethnic cohort of middle aged and older adults to examine associations between neighborhood environments and incidence of obesity (where the neighborhood environment is characterized using informant reports of the neighborhood). We hypothesized that neighborhood suitability for walking and buying healthy foods reduces obesity risk.

\section{METHODS \\ PERSON-LEVEL DATA}

Person-level data came from MESA, a longitudinal study of risk factors for atherosclerosis, [19] which recruited participants aged 45-84 years from six field centers (New York and Bronx counties, New York; Baltimore City and County, Maryland; Forsyth County, North Carolina; Chicago, Illinois; St. Paul, Minnesota; and Los Angeles, California). A variety of population-based approaches were used for recruiting, including commercial lists of area residents and random digit dialing (for more details see www.mesa-nhlbi.org/ and Bild (2002) [19]). Only persons free from clinical cardiovascular disease (CVD) at baseline were eligible. Data were used from the baseline exam (collected 2000-2002) and three follow-up exams which occurred approximately 1.6, 3.1, and 4.8 years later (last data collection was May 2007); participant retention rates were $94 \%, 89 \%$, and 86\%, respectively. All participants provided written informed consent and the study was approved by the Institutional Review Boards at all participating institutions.

\section{MEASUREMENT OF OBESITY AND COVARIATES}

BMI was calculated from measured weight and height at physical examinations at each follow-up visit (weight $/$ height in $\mathrm{kg} / \mathrm{m}^{2}$ ). Obesity was defined as BMI $>=30 \mathrm{~kg} / \mathrm{m}^{2}$ and a person was classified as having incident obesity the first time their BMI reached this threshold regardless of subsequent BMI. Covariates were measured at baseline via study 
questionnaire. Socio-demographic characteristics included age, sex, self-reported race/ ethnicity, acculturation index (immigrant status, years in the US, language spoken at home [20]), per capita household income, household assets [21] (owns home, investments, property other than primary home), and education. Other covariates include cigarette smoking status, physical activity, and diet (see Table 1 for categorization scheme).

Physical activity during a typical week was assessed using a detailed, standardized, semiquantitative questionnaire adapted from the Cross-Cultural Activity Participation Study [19, 22] and total metabolic equivalent task-minutes (MET) were estimated for a combination of walking, moderate and vigorous intensity sports, and conditioning activities (as previously reported $[19,23])$. From this hours per day of physical activity was derived and to improve interpretability of this variable, the variable was classified into tertiles in regression models.

Dietary measurements, compiled from a food frequency questionnaire (as previously reported [24]), were used to derive an index of a healthy diet, "the alternate healthy eating index" [25] which has been used in previous work [26] because it strongly correlates with major chronic disease and CVD risk.[25] The index ranges from 2.5 to 87.5, and higher scores indicate a better quality diet (higher intake of fruits, vegetables, soy, protein, white meat, cereal ber, polyunsaturated fat, and multivitamins and lower intake of alcohol, saturated fat, and red meat). All data were collected at follow-up exams except for dietary measures (see Supplement Table 1 for details).

\section{NEIGHBORHOOD DATA}

During 2003-2005, MESA participants were enrolled in an ancillary study, the MESA Neighborhood Study (see details [27, 28]). Residents were asked to refer to the area within about a 20-minute walk or about a mile from their home and they provided a one-time report on a number of neighborhood-level domains potentially related to CVD. Two scales were used in this study: one that assessed the walking environment and another that assessed the availability of healthy foods. Items were derived from published work whenever possible (see details here [27, 28]). Residents were asked if it was "pleasant" and "easy" to walk to places in their neighborhood, and if a large selection of fruits, vegetables, and low-fat foods was available nearby for purchase (see Supplement Table 2). Each item within a scale had a 5 -point response option and within-scale items were averaged. Scale internal consistency was acceptably high for walking environment and availability of healthy foods ( 0.61 and 0.90 respectively) as reported in previous work[29]. Responses for residents living within 1 mile of the MESA referent person were averaged to create a measure of the neighborhood characteristics for each MESA residential address at baseline (henceforth referred to as informant reports of the neighborhood). Averaged informant reports of the neighborhood did not include the MESA respondent's report of their own neighborhood to avoid spurious associations that can result when neighborhood information and behaviors are self-reported by the same subjects.[30] One mile was used to proxy MESA participants' neighborhoods. The 1 mile buffer corresponded to the neighborhood survey which asked respondents to report on the area within about a 20-minute walk or about a mile from your home and has frequently used in federal government definitions of access to services thus is relevant to policy.[31] 


\section{PARTICIPANTS INCLUDED IN STUDY}

Of the 6814 persons enrolled at baseline, 6191 participated in the ancillary study [19].

Analyses performed for incident obesity excluded persons obese at baseline (32\%, $\mathrm{n}=1976)$.

Additional persons were excluded due to address errors ( $n=97)$, missing neighborhood-level exposures $(n=60)$, or key covariates $(n=50)$. (See Results for comparison of included vs. excluded.) A total of 4008 participants were included in the descriptive analyses and initial series of regression models to preserve the sample as much as possible. An additional 299 persons did not complete the dietary questionnaire and thus were further excluded when controlling for diet; excluding these observations did not affect the estimates of interest but these observations were kept in the initial series of models in order to preserve statistical power.

\section{STATISTICAL ANALYSES}

We first examined the distribution of individual-level variables for persons who did and did not become obese during follow-up; and the distribution of neighborhood variables across the person-level variables. Poisson regression was used to estimate age-adjusted incidence rates for tertiles of neighborhood exposures by sex.[32, 33] Pooled results are shown for all subsequent analyses because patterning of rates across neighborhood exposures were roughly similar for women and men; in regression models statistical significance for sex interactions was $\mathrm{p}>0.2$, and in adjusted models stratification by sex showed similarity of neighborhood effects.

Proportional hazards regression was used to derive hazards ratios for associations of informant reports of the neighborhood with incident obesity, after adjustment for age, sex, race/ethnicity, acculturation to US, income, household assets, education, cigarette smoking status, diet, and physical activity. When variables were assessed during interim years (see Supplement Table 1) they were specified as time-varying in the regression models. Hazard ratios were examined before and after baseline BMI was included, and before and after adjustment for the other neighborhood measure (informant reports of neighborhood food and walking environments were examined adjusted for each other). Adjustment for baseline BMI was necessary due to unequal population distributions of baseline BMI across neighborhood environments. All models included baseline age, age squared, race/ethnicity, acculturation score, income, assets, education, education squared, and cigarette smoking status. [2-13] Squared terms were used after diagnosing non-linearity of adjusted effects between covariates and the response variable. Multicollinearity diagnostics indicated acceptable variance inflation factors (VIF) when both neighborhood scores were in the regression model, VIF $<3$. To compare associations for neighborhood variables that have different units, estimates shown correspond to differences in 1 standard deviation unit (translating to differences of 0.32 in the walking scale [Range 2.00-4.91], and 0.60 in the healthy foods scale [Range 1.00-5.00]. Because some respondents reside near each other, a robust covariance matrix estimator (sandwich estimator) was used for all regression models to account for clustering of observations within tracts.[34, 35]

Interactions-Based on prior literature, we tested whether the following baseline variables modified the association between informant reports of the neighborhood and incident 
obesity: income, race/ethnicity, education, study site, overweight at baseline; car ownership (which may suggest the degree to which households may be constrained to their neighborhood), and dose of neighborhood exposure (years of residence in the neighborhood and whether participants moved from their baseline address).

\section{RESULTS \\ Descriptive}

At baseline, of the 6191 total MESA participants, $71 \%$ of the sample was overweight and $32 \%$ were obese (Table 1). Persons obese at baseline were excluded from the incident analyses. Differences between included and excluded participants were statistically significant for a number of covariates (see Table 1 footnote) but substantively important differences were only observed for race ethnic differences (one-third to one-half of Black and Hispanic women were excluded due to baseline obesity). Compared to the total population, the 4008 participants not obese at baseline included in the analyses had a lower percent African American and more favorable physical activity profile. Among those overweight at baseline, $18 \%$ became obese over the follow-up, compared to only $2 \%$ among those with normal weight at baseline.

Persons with higher income, education, and better diet and physical activity profiles tended to live in areas with more favorable neighborhood informant reports of suitability for walking (test for trend $<0.001$ ) and buying healthy foods (test for trend $<0.001$ ), although the gradient was more apparent for healthy foods (Table 2). White persons lived in areas with the highest food environment score, while Chinese and Hispanics lived in areas with the highest walking environment score.

More favorable reports on neighborhood access to healthy foods were associated with a graded reduction in age-adjusted obesity incidence rates with the association being more marked for healthy food environment (Figure 1). Incidence patterns were roughly similar for males and females and p-values for sex by environment interactions in adjusted models were $p>0.1$ for healthy eating environment on obesity and $p>0.2$ for all other models. Because sex stratification did not enhance the substantive findings and reduced power, subsequent results are reported for the pooled sample. Pooled across sex, among persons living in the worst, intermediate, and best neighborhoods for healthy foods, the per 1000 person-years obesity incidence was $31.4,20.4$, and 17.8, respectively. Obesity incidence was lowest for those living in better walking environments but the gradient was less clear.

\section{Adjusted models - incidence of obesity}

More favorable reports on neighborhood access to healthy foods were associated with lower obesity incidence throughout most phases of adjustment. Neighborhood resources that support walking had a weaker association, and confidence intervals included the null in all models except for the model that did not adjust for baseline BMI or healthy food environment. Table 3, column A shows the association of neighborhood score with incident obesity. Adjusting for age, sex, race/ethnicity, acculturation score, socio-economic status (family income, assets), and cigarette smoking, obesity incidence during follow-up was $18 \%$ 
lower per each 1 STD increase in favorable food environment (model $1 \mathrm{~A}$, hazard ratio [HR] $0.82,95 \%$ confidence interval [CI]: 0.75, 0.90) and $11 \%$ lower per each STD increase in favorable walking environment (model 1 A, HR 0.89, CI: 0.81, 0.98). Additional adjustment for individual level exercise and diet did not affect the magnitude of the association substantially, although there was a slight attenuation (model 2 A). Table 3, column B shows the estimated association after accounting for baseline BMI: the association was slightly weaker but persisted (model 2 B, HR 0.88, 95\% CI: 0.79, 0.97 for food environment and HR 0.90, 95\% CI: 0.81, 1.00 for walking environment). After further adjustment for correlated neighborhood features, confidence intervals widened to include the null for food environment while the association for walking environment completely disappeared (model 4 B, HR 0.89, 95\% CI: $0.77,1.03$ for healthy foods, HR $0.98,95 \%$ CI: $0.84,1.15$ for walking environment).

\section{Heterogeneity of associations}

Heterogeneity of associations was examined, adjusted for age, sex, income, assets, education, race/ethnicity, acculturation score, cigarette smoking status, exercise, diet, and baseline body mass index. Heterogeneity was statistically significant for some factors but on a substantive level, differences between strata were minor (see Supplement Table 3). Neighborhood food environment was most protective among persons not overweight at baseline. Neighborhood physical activity environment was most protective among persons with lower income and persons who lived in the neighborhood less than 15 years (the median number of years). While associations of neighborhood food and physical activity environment with obesity differed by education there was no clear pattern. No statistically significant differences were found by race/ethnicity, enrollment study site, car ownership, and moved during follow-up ( $\mathrm{p}>=0.05$, not shown). Twenty percent of participants moved from their neighborhood at some point during the follow-up period. The new neighborhoods shared similar characteristics to their baseline neighborhood (Pearson correlations between pre- and post-move neighborhood scores was 0.60 , not shown) and the neighborhood association with obesity incidence was not statistically different between movers and nonmovers.

\section{DISCUSSION}

In this longitudinal study of aging adults, more favorable neighborhood informant reports of access to healthy foods were associated with a $12 \%$ lower obesity incidence even after adjustment for numerous risk factors for obesity and for baseline BMI (HR 0.88, 95\% CI: $0.79,0.97)$. The magnitude of the association persisted even after adjustment for correlated features of the walking environment although confidence intervals widened to include the null (HR 0.89, 95\% CI: 0.77, 1.03). Similarly, favorable neighborhood informant reports regarding the suitability of the walking environment was associated with $10 \%$ lower obesity incidence after adjustment for risk factors and baseline BMI (HR 0.90, 95\% CI: 0.81, 1.00) although the association was not independent of correlated neighborhood healthy eating amenities. 
There is a lack longitudinal work to compare with our results. Prior cross-sectional studies estimating the likelihood of obesity with increases in favorable neighborhood physical environments anchored reasonably well to the baseline results from this study, thus lending confidence in estimates reported here [6,36-38]. One of the challenges for studying the determinants of new cases of obesity in the U.S. is the high baseline prevalence of adult overweight and obese. One-third of the cohort was excluded due to being obese at baseline. This may limit generalizability of the results, particularly generalizability to Black and Hispanic women since one-third to one-half of these persons were excluded due to baseline obesity. Nevertheless, the study was able to detect associations between protective features of the environment and obesity (BMI $>=30 \mathrm{~kg} / \mathrm{m}^{2}$ ) which persisted after conditioning on baseline weight (BMI). In addition, the high prevalence of baseline obesity prevented analyses of incidence of overweight (BMI $25-<30 \mathrm{~kg} / \mathrm{m}^{2}$ ) since $58 \%$ of the sample would have to have been excluded. Incidence of severe obesity (BMI $>=35 \mathrm{~kg} / \mathrm{m}^{2}$ ), which has been most strongly associated with excess mortality [39] also could not be examined due to low incidence during 5 years of follow-up.

Researchers have used at least four methods to assess neighborhood walkability and availability of high-quality healthy foods: survey-derived participant perceptions and community perceptions, ground audits, and commercial listings or other remotely collected GIS data (for reviews of these methods see [40-42]). Utilizing diverse assessment methods, constructs that assess neighborhood walkability and availability of high-quality healthy foods have been shown to have roughly similar rankings (excluding safety from crime) but they do not perfectly concur; this is likely because they measure different aspects of the same construct.[43-45] Due to the expense of ground audits, almost all studies have used survey-derived participant perceptions or remotely collected GIS data. Resident surveys can capture dimensions that are difficult if not impossible to measure using commercial listings or other remotely collected GIS data: access, quality, and usability of resources. A strength of the current study is that neighborhood amenities were assessed by persons other than the MESA referent person thus results were not likely systematically biased by the correlation between self-perceived community-level amenities and self-reported behaviors.[30]

The current study asked community residents whether there was a large selection of fresh fruits and vegetables and low fat products in their neighborhood. These do not capture all dimensions of healthy food availability but have frequently been used as markers to proxy availability of healthy options in retail environments.[46] A 1-mile area was used to crudely approximate participant exposure to this measure. This distance has frequently used in federal government definitions of access to services thus is relevant to policy.[31] Studies have generally showed low sensitivity to use of 1-mile or larger area nevertheless it is plausible that measurement error in the relevant geographic scale for accessing healthy food and walkable neighborhoods reduced our ability to detect a stronger association.[47] In addition, models that included both food and walking environment variables did not consistently detect an association with obesity independent of the other neighborhood factor likely in part due to the collinearity between these two measures which made it difficult to detect independent associations with incident obesity. 
Most participants resided for a long period (median of 17 years) in their neighborhood; thus, to the extent that neighborhood environments remain stable over time, participants may have had long-term exposure to their neighborhood's resources. The neighborhood association with obesity incidence was not statistically different between movers and non-movers likely due to participants relocating to neighborhoods that shared similar characteristics to their baseline neighborhood [48] (as indicated by high correlations between pre- and post-move neighborhood scores).

This is the first study to examine neighborhood resources for healthy eating and walkability with incident obesity in a large multi-site US population-based, multiethnic sample. Results suggest that a relatively modest improvement in neighborhood environments (equivalent to a 1 SD change in our sample) would reduce obesity incidence by $10 \%$. Having healthy foods easily available and designing walkable residential environments will not reverse the obesity epidemic by themselves but may play an important role in combination with other facilitators of healthy behaviors. There are no easy answers to halting the obesity epidemic; prevention strategies will need to be adopted in most facets of daily life. However, suitable environments are likely to be a pre-condition for sustaining existing healthy behaviors and for adopting new healthy behaviors.

\section{Supplementary Material}

Refer to Web version on PubMed Central for supplementary material.

\section{Acknowledgments}

\section{FUNDING}

This research was supported by grant 2R01 HL071759 (PI: Diez Roux) and contracts N01-HC-95159 through N01HC-95169 from the National Heart, Lung, and Blood Institute. The authors thank the other investigators, the staff, and the participants of the MESA study for their valuable contributions. A full list of participating MESA investigators and institutions can be found at http://www.mesa-nhlbi.org.

\section{References}

1. Abbasi F, Brown BW, Lamendola C, McLaughlin T, Reaven GM. Relationship between obesity, insulin resistance, and coronary heart disease risk. Journal of the American College of Cardiology. 2002 Sep 4; 40(5):937-43. [PubMed: 12225719]

2. Aneja A, El-Atat F, McFarlane SI, Sowers JR. Hypertension and obesity. Recent progress in hormone research. 2004; 59:169-205. [PubMed: 14749502]

3. van Uffelen JGZ, Berecki-Gisolf J, Brown WJ, Dobson AJ. What Is a Healthy Body Mass Index for Women in Their Seventies? Results From the Australian Longitudinal Study on Women's Health. The Journals of Gerontology Series A: Biological Sciences and Medical Sciences. Aug 1; 2010 65A(8):847-53.

4. Blumenthal SJ, Hendi JM, Marsillo L. A public health approach to decreasing obesity. JAMA. 2002 Nov 6.288(17):2178. [PubMed: 12413384]

5. Morland K, Diez Roux AV, Wing S. Supermarkets, other food stores, and obesity: the Atherosclerosis Risk in Communities Study. American journal of preventive medicine. 2006 Apr; 30(4):333-9. [PubMed: 16530621]

6. Morland KB, Evenson KR. Obesity prevalence and the local food environment. Health \& place. 2009 Jun; 15(2):491-5. [PubMed: 19022700] 
7. Holsten JE. Obesity and the community food environment: a systematic review. Public Health Nutr. 2009 Mar; 12(3):397-405. [PubMed: 18477414]

8. Wang MC, Cubbin C, Ahn D, Winkleby MA. Changes in neighbourhood food store environment, food behaviour and body mass index, 1981-1990. Public Health Nutr. 2007 Sep.26:1-8.

9. Berke EM, Koepsell TD, Moudon AV, Hoskins RE, Larson EB. Association of the built environment with physical activity and obesity in older persons. American journal of public health. 2007 Mar; 97(3):486-92. [PubMed: 17267713]

10. Papas MA, Alberg AJ, Ewing R, Helzlsouer KJ, Gary TL, Klassen AC. The built environment and obesity. Epidemiologic reviews. 2007; 29:129-43. [PubMed: 17533172]

11. Sallis JF, Glanz K. Physical activity and food environments: solutions to the obesity epidemic. Milbank Q. 2009 Mar; 87(1):123-54. [PubMed: 19298418]

12. Saelens BE, Handy SL. Built environment correlates of walking: a review. Medicine and science in sports and exercise. 2008 Jul; 40(7 Suppl):S550-66. [PubMed: 18562973]

13. Mujahid MS, Roux AV, Shen M, Gowda D, Sanchez B, Shea S, et al. Relation between neighborhood environments and obesity in the Multi-Ethnic Study of Atherosclerosis. Am J Epidemiol. 2008 Jun 1; 167(11):1349-57. [PubMed: 18367469]

14. Larson NI, Story MT, Nelson MC. Neighborhood environments disparities in access to healthy foods in the U.S. American journal of preventive medicine. 2009 Jan; 36(1):74-81. e10. [PubMed: 18977112]

15. Stafford M, Brunner EJ, Head J, Ross NA. Deprivation and the development of obesity a multilevel, longitudinal study in England. American journal of preventive medicine. 2010 Aug; 39(2):130-9. [PubMed: 20621260]

16. Ruel E, Reither EN, Robert SA, Lantz PM. Neighborhood effects on BMI trends: Examining BMI trajectories for Black and White women. Health \& place. 2010; 16(2):191-8. [PubMed: 19879795]

17. Coogan PF, Cozier YC, Krishnan S, Wise LA, Adams-Campbell LL, Rosenberg L, et al. Neighborhood Socioeconomic Status in Relation to 10-Year Weight Gain in the Black Women's Health Study. Obesity. 2010; 18(10):2064-5. [PubMed: 20360755]

18. Berry TR, Spence JC, Blanchard C, Cutumisu N, Edwards J, Nykiforuk C. Changes in BMI over 6 years: the role of demographic and neighborhood characteristics. International journal of obesity (2005). 2010 Aug; 34(8):1275-83. [PubMed: 20157324]

19. Bild DE, Bluemke DA, Burke GL, Detrano R, Diez Roux AV, Folsom AR, et al. Multi-Ethnic Study of Atherosclerosis: objectives and design. Am J Epidemiol. 2002 Nov 1; 156(9):871-81. [PubMed: 12397006]

20. Kandula NR, Diez-Roux AV, Chan C, Daviglus ML, Jackson SA, Ni H, et al. Association of acculturation levels and prevalence of diabetes in the multi-ethnic study of atherosclerosis (MESA). Diabetes care. 2008 Aug; 31(8):1621-8. [PubMed: 18458142]

21. Robert S, House JS. SES differentials in health by age and alternative indicators of SES. J Aging Health. 1996 Aug; 8(3):359-88. [PubMed: 10165980]

22. LaMonte MJ, Durstine JL, Addy CL, Irwin ML, Ainsworth BE. Physical activity, physical fitness, and Framingham 10-year risk score: the Cross-Cultural Activity Participation study. J Cardiopulm Rehabil. 2001 Mar-Apr;21(2):63-70. [PubMed: 11314285]

23. Bertoni AG, Whitt-Glover MC, Chung H, Le KY, Barr RG, Mahesh M, et al. The association between physical activity and subclinical atherosclerosis: the Multi-Ethnic Study of Atherosclerosis. American journal of epidemiology. 2009 Feb 15; 169(4):444-54. [PubMed: 19075250]

24. Nettleton JA, Steffen LM, Mayer-Davis EJ, Jenny NS, Jiang R, Herrington DM, et al. Dietary patterns are associated with biochemical markers of inflammation and endothelial activation in the Multi-Ethnic Study of Atherosclerosis (MESA). The American journal of clinical nutrition. 2006 Jun; 83(6):1369-79. [PubMed: 16762949]

25. McCullough ML, Willett WC. Evaluating adherence to recommended diets in adults: the Alternate Healthy Eating Index. Public Health Nutr. 2006 Feb; 9(1A):152-7. [PubMed: 16512963]

26. Moore LV, Diez Roux AV, Nettleton JA, Jacobs DR, Franco M. Fast-food consumption, diet quality, and neighborhood exposure to fast food: the multi-ethnic study of atherosclerosis. Am J Epidemiol. 2009 Jul 1; 170(1):29-36. [PubMed: 19429879] 
27. Echeverria SE, Diez-Roux AV, Link BG. Reliability of self-reported neighborhood characteristics. J Urban Health. 2004 Dec; 81(4):682-701. [PubMed: 15466849]

28. Mujahid MS, Diez Roux AV, Morenoff JD, Raghunathan T. Assessing the measurement properties of neighborhood scales: from psychometrics to ecometrics. Am J Epidemiol. 2007 Apr 15; 165(8): 858-67. [PubMed: 17329713]

29. Osypuk TL, Roux AV, Hadley C, Kandula NR. Are immigrant enclaves healthy places to live? The Multi-ethnic Study of Atherosclerosis. Social science \& medicine (1982). 2009 Jul; 69(1): 110-20. [PubMed: 19427731]

30. Raudenbush SW, Sampson RJ. Ecometrics: Toward a science of assessing ecological settings, with application to the systematic social observation of neighborhoods. Sociological Methodology. 1999; 29:1-41.

31. Ver Ploeg, M.; Breneman, V.; Farrigan, T.; Hamrick, K.; Hopkins, D.; Kaufman, P., et al. Access to Affordable and Nutritious Food-Measuring and Understanding Food Deserts and Their Consequences: Report to Congress. United States Department of Agriculture; 2009.

32. Joffe MM, Greenland S. Standardized estimates from categorical regression models. Statistics in medicine. 1995 Oct 15; 14(19):2131-41. [PubMed: 8552892]

33. Zhao, D. Poisson Regression Adjustment of Event Rates and Its Macro Procedure ADJ_POIS. SAS Users Group International; 1999; Miami Beach, Florida: SAS Conference Proceedings; 1999. [http://www2.sas.com/proceedings/sugi24/Posters/p256-24.pdf]

34. Wei LJ, Lin DY, Weissfeld L. Regression-Analysis of Multivariate Incomplete Failure Time Data by Modeling Marginal Distributions. Journal of the American Statistical Association. 1989 Dec; 84(408):1065-73.

35. SAS. SAS/STAT 9.2 User's Guide. 2. SAS Institute Inc; 2011. http://support.sas.com/ documentation/cdl/en/statug/63033/HTML/default/viewer.htm\#statug_phreg_a0000000690.htm

36. Boehmer TK, Hoehner CM, Deshpande AD, Brennan Ramirez LK, Brownson RC. Perceived and observed neighborhood indicators of obesity among urban adults. International journal of obesity (2005). 2007 Jun; 31(6):968-77. [PubMed: 17224932]

37. Lovasi GS, Hutson MA, Guerra M, Neckerman KM. Built environments and obesity in disadvantaged populations. Epidemiologic reviews. 2009; 31:7-20. [PubMed: 19589839]

38. Rundle A, Neckerman KM, Freeman L, Lovasi GS, Purciel M, Quinn J, et al. Neighborhood food environment and walkability predict obesity in New York City. Environ Health Perspect. 2009 Mar; 117(3):442-7. [PubMed: 19337520]

39. Flegal KM, Graubard BI, Williamson DF, Gail MH. Excess deaths associated with underweight, overweight, and obesity. Jama. 2005 Apr 20; 293(15):1861-7. [PubMed: 15840860]

40. Glanz K. Measuring Food Environments: A Historical Perspective. American journal of preventive medicine. 2009; 36(4, Supplement 1):S93-S8. [PubMed: 19285215]

41. Sallis JF. Measuring Physical Activity Environments: A Brief History. American journal of preventive medicine. 2009; 36(4, Supplement 1):S86-S92. [PubMed: 19285214]

42. Matthews SA, Moudon AV, Daniel M. Work Group II: Using Geographic Information Systems for Enhancing Research Relevant to Policy on Diet, Physical Activity, and Weight. American journal of preventive medicine. 2009; 36(4, Supplement 1):S171-S6. [PubMed: 19285210]

43. Moore LV, Diez Roux AV, Brines S. Comparing Perception-Based and Geographic Information System (GIS)-based characterizations of the local food environment. J Urban Health. 2008 Mar; 85(2):206-16. [PubMed: 18247121]

44. Rodriguez DA, Evenson KR, Diez Roux AV, Brines SJ. Land use, residential density, and walking. The multi-ethnic study of atherosclerosis. American journal of preventive medicine. 2009 Nov; 37(5):397-404. [PubMed: 19840694]

45. Freedman DA, Bell BA. Access to Healthful Foods among an Urban Food Insecure Population: Perceptions versus Reality. Journal of Urban Health-Bulletin of the New York Academy of Medicine. 2009 Nov; 86(6):825-38. [PubMed: 19898939]

46. Larson N, Story M. A review of environmental influences on food choices. Ann Behav Med. 2009 Dec; 38(Suppl 1):S56-73. [PubMed: 19802648] 
47. Coulton C, Korbin J, Chan T, Su M. Mapping Residents' Perceptions of Neighborhood Boundaries: A Methodological Note. American Journal of Community Psychology. 2001; 29(2): 371-83. [PubMed: 11446289]

48. Crowder K, South SJ, Chavez E. Wealth, Race, and Inter-Neighborhood Migration. American Sociological Review. 2006; 71:72-94. 


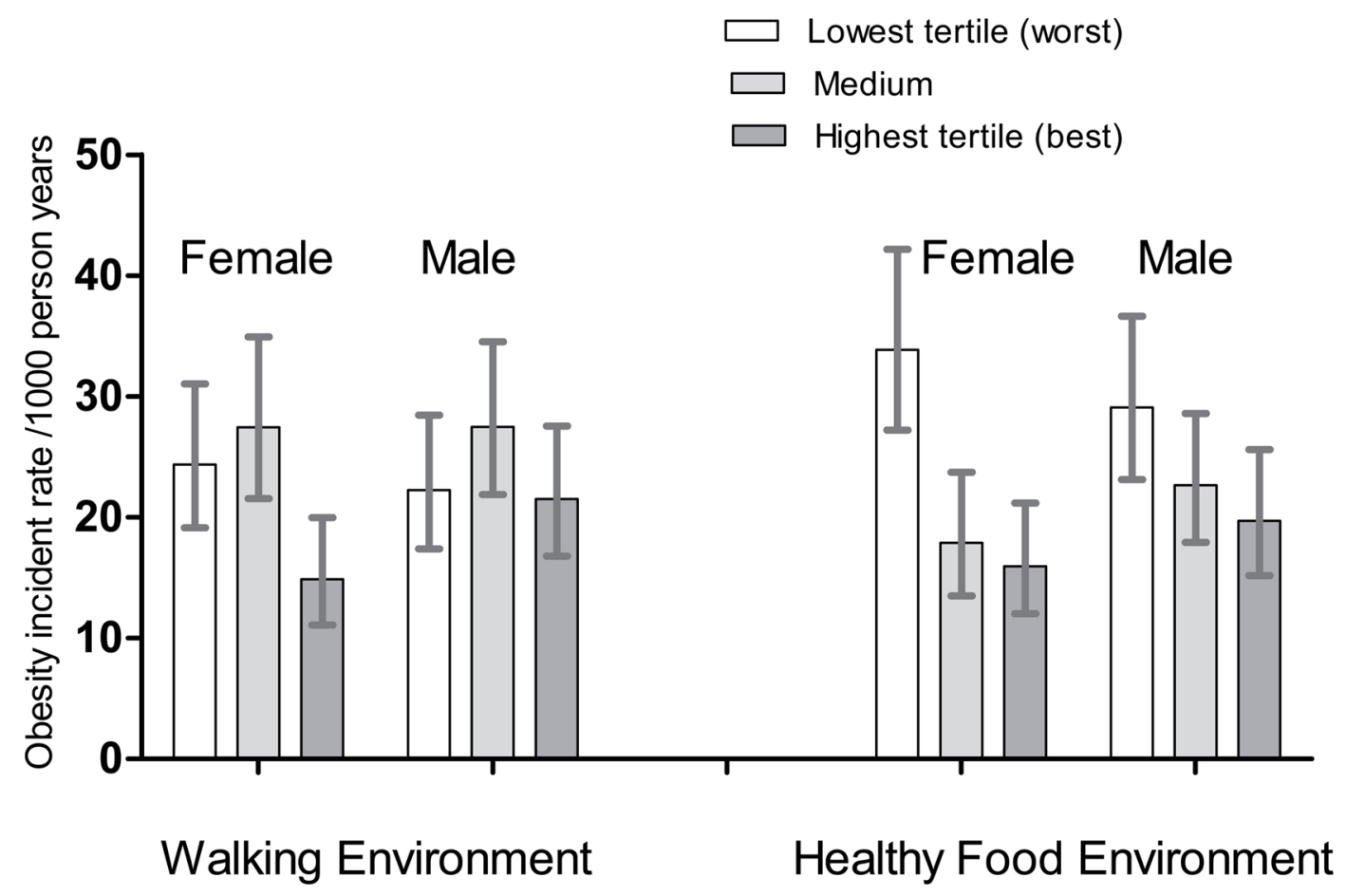

Figure 1.

Obesity incidence rates per 1000 person years (with 95\% confidence intervals) across tertiles of neighborhood scores; MESA, 2000-2007. 


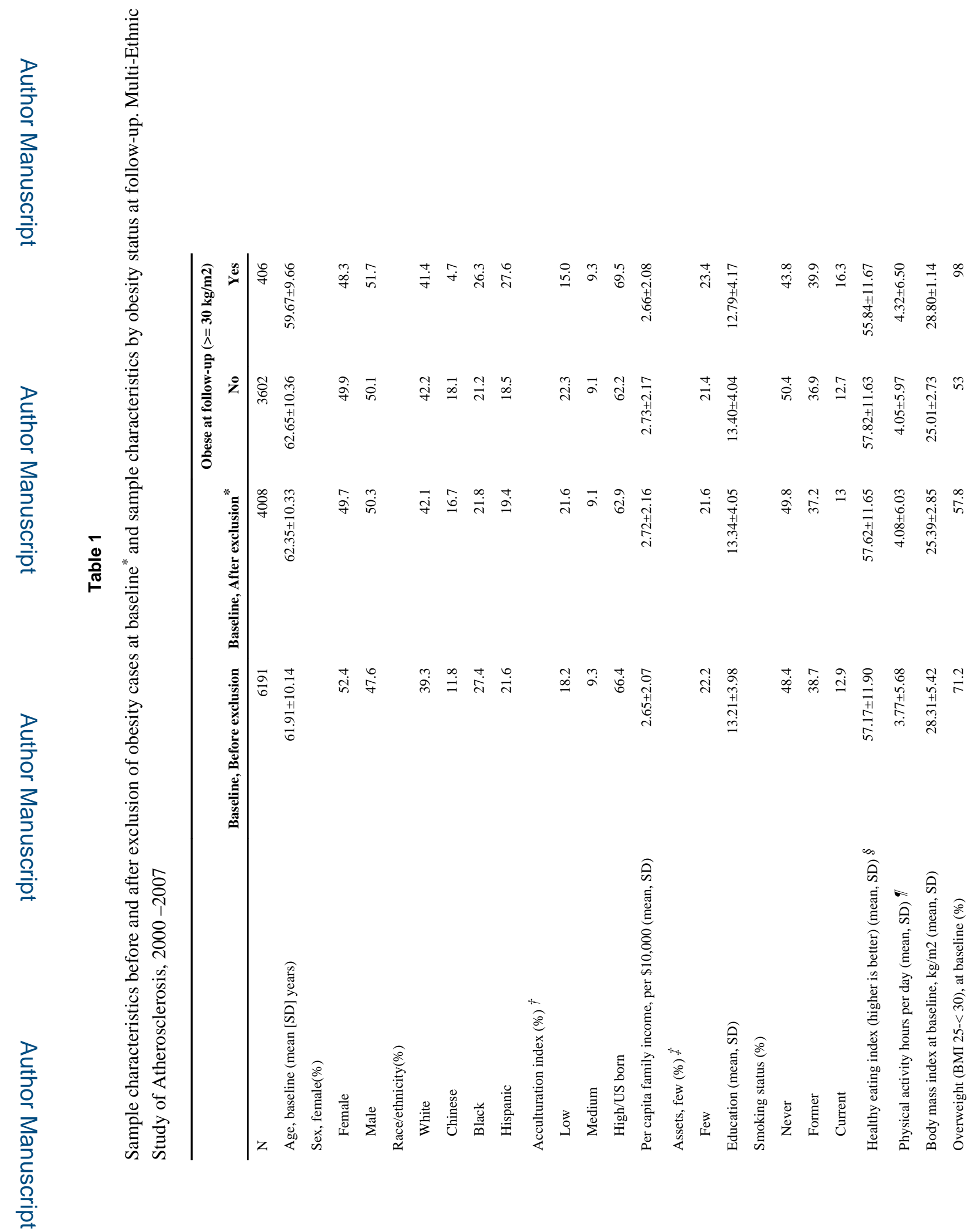

Obesity (Silver Spring). Author manuscript; available in PMC 2013 October 19. 


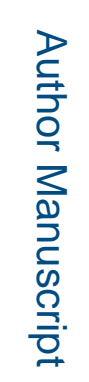

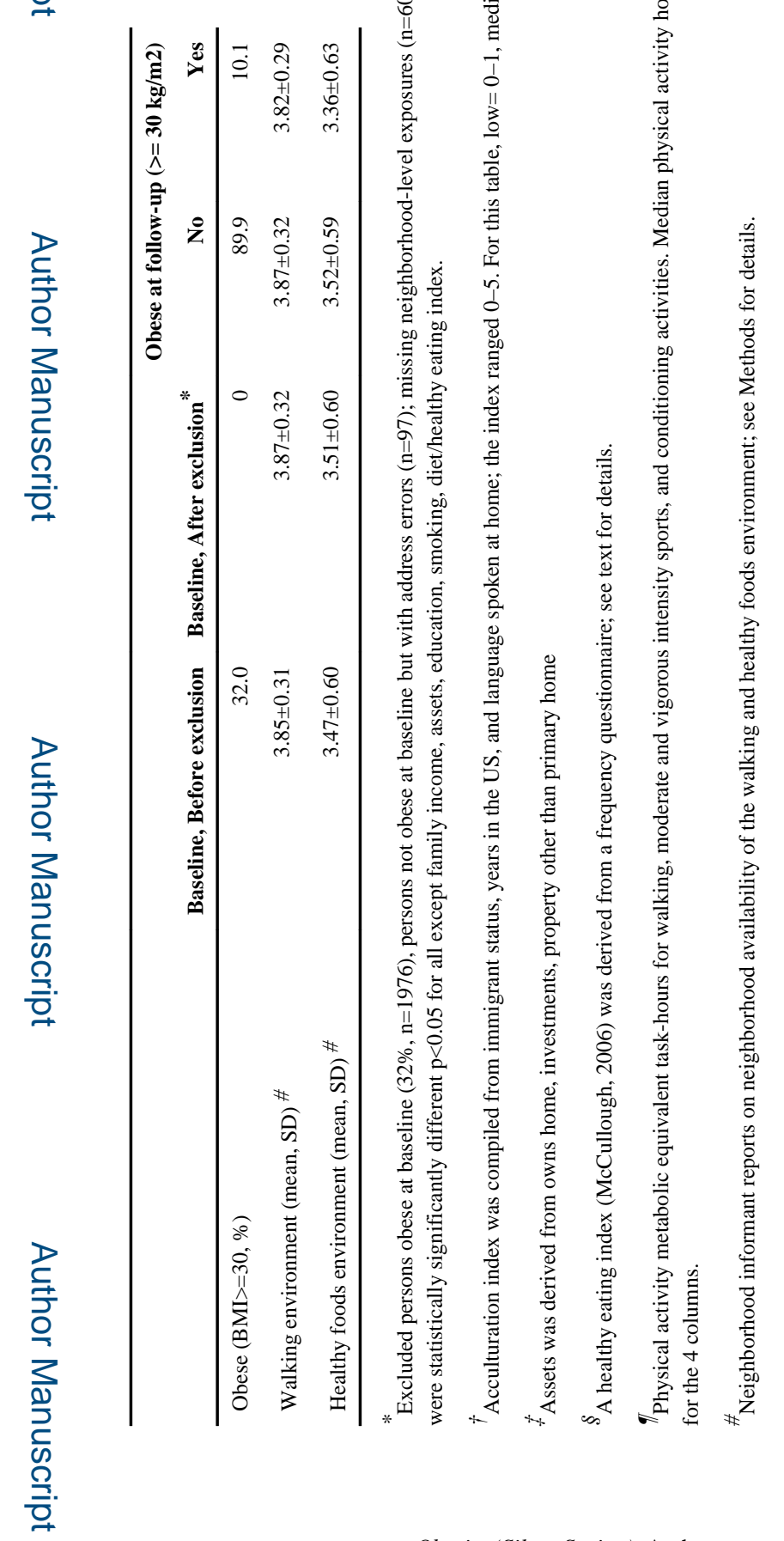




\section{Table 2}

Neighborhood characteristics by person-level characteristics*. Multi-Ethnic Study of Atherosclerosis, 2000 $2007, \mathrm{n}=4008$.

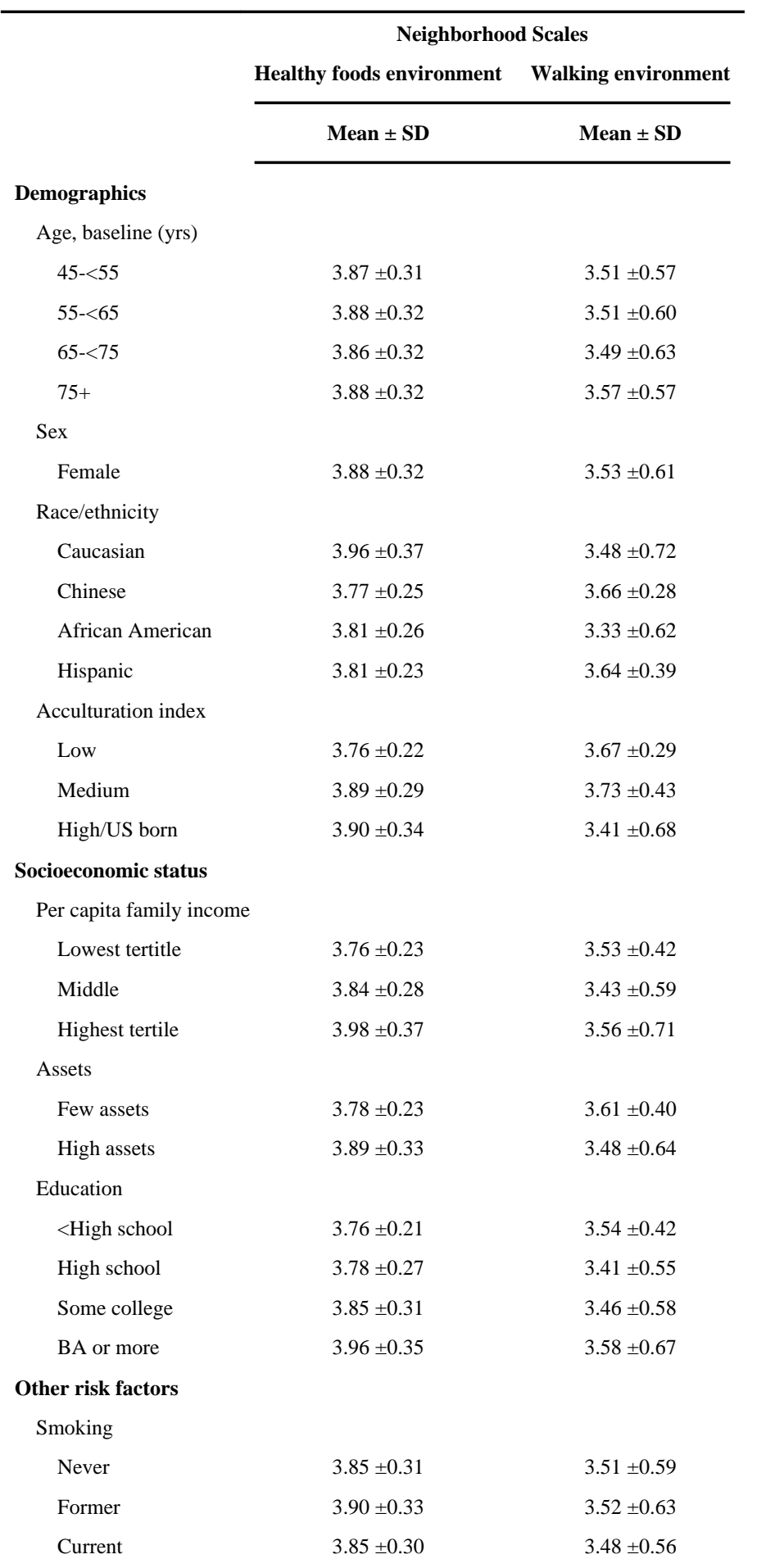




\begin{tabular}{lcc}
\hline & \multicolumn{2}{c}{$\begin{array}{c}\text { Neighborhood Scales } \\
\text { Healthy foods environment }\end{array}$} \\
\cline { 2 - 3 } & Walking environment \\
\cline { 2 - 3 } & Mean \pm SD & Mean \pm SD \\
\hline Healthy eating index (higher is better) & \\
Low tertile & $3.83 \pm 0.30$ & $3.45 \pm 0.58$ \\
Middle tertile & $3.87 \pm 0.32$ & $3.52 \pm 0.59$ \\
High tertile & $3.90 \pm 0.34$ & $3.55 \pm 0.62$ \\
Physical activity hours per day & & \\
Low tertile & $3.79 \pm 0.29$ & $3.46 \pm 0.55$ \\
Middle tertile & $3.87 \pm 0.31$ & $3.51 \pm 0.59$ \\
High tertile & $3.93 \pm 0.33$ & $3.56 \pm 0.64$ \\
Body mass index, $\mathrm{kg} / \mathrm{m}^{2}$ & & $3.57 \pm 0.60$ \\
$<25$ & $3.89 \pm 0.33$ & $3.47 \pm 0.59$ \\
\hline $25-<30$, overweight & $3.85 \pm 0.31$ &
\end{tabular}

* Tests for trend were $<0.001$ for physical activity hours and walking environment and healthy eating and healthy food environment. 


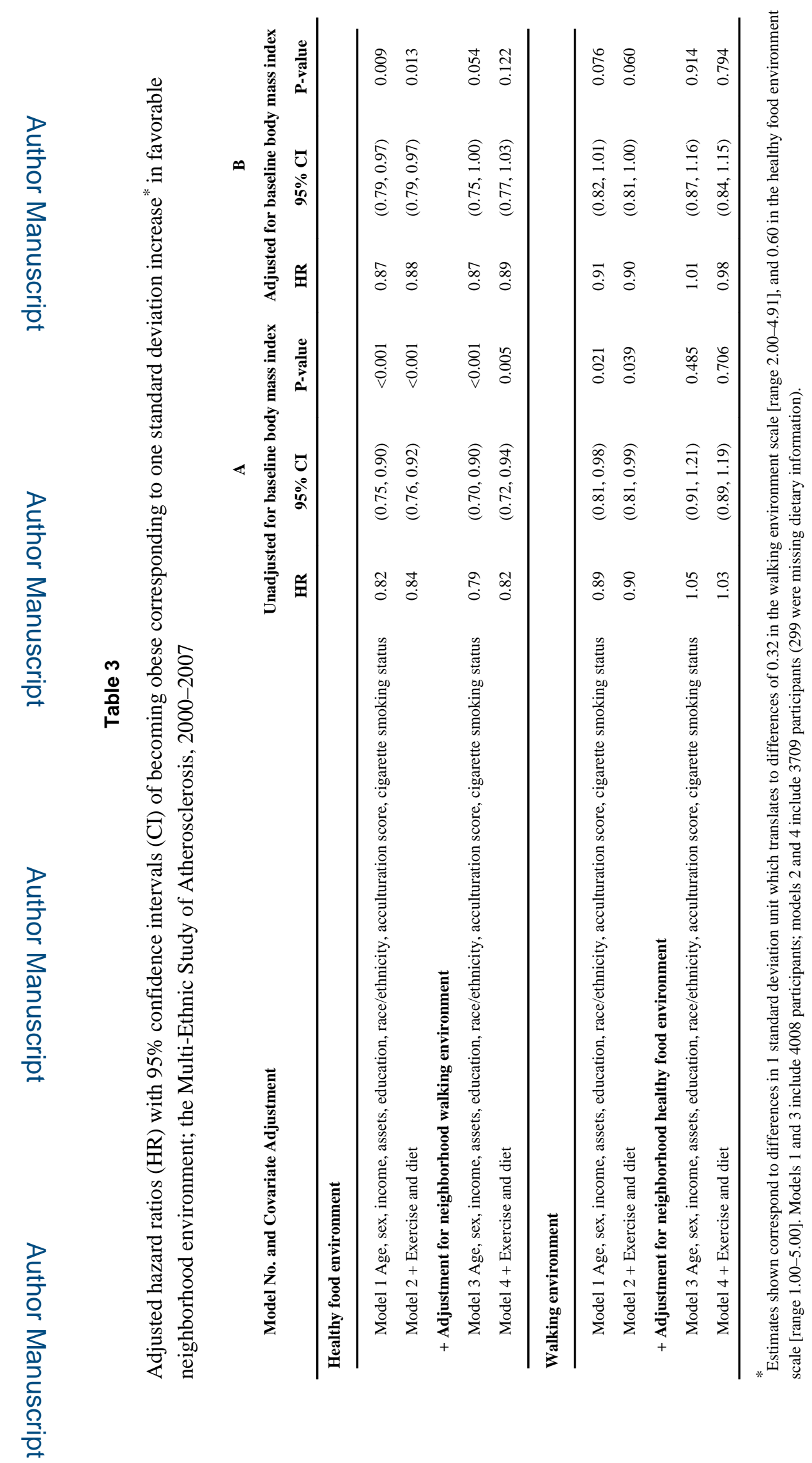

Obesity (Silver Spring). Author manuscript; available in PMC 2013 October 19. 